\title{
DEGENERATIVE LUMBAR STENOSIS
}

\section{Update}

\author{
Andrei F. Joaquim', Charles A. Sansur', David K. Hamilton², Christopher I. Shaffrey ${ }^{2,3}$
}

\begin{abstract}
We present a literature review of the diagnosis and treatment of acquired lumbar spinal stenosis (LS), with a brief description of new surgical techniques. LS is the most common cause of spinal surgery in individuals older than 65 years of age. Neurogenic claudication and radiculopathy result from compression of the cauda equina and lumbosacral nerve roots by degenerated spinal elements. Surgical decompression is a well established treatment for patients with refractory, or moderate to severe clinical symptoms. However, the variety of surgical options is vast. New techniques have been developed with the goal of increasing long term functional outcomes. In this article we review lumbar decompression and fusion as treatment options for LS but also present other recent developments. Prospective long term studies are necessary to know which procedures would result in optimal patient outcome.
\end{abstract}

KEY WORDS: acquired lumbar stenosis, surgical treatment, new techniques, fusion.

\section{Estenose lombar degenerativa: atualização}

Resumo - Apresentamos uma revisão de literatura do diagnóstico e tratamento da estenose lombar (EL) adquirida, enfatizando as novas técnicas de manejo cirúrgico. A EL é a causa mais comum de cirurgia na coluna de pacientes com mais de 65 anos de idade. Claudicação neurogênica e radiculopatias são sintomas resultantes da compressão das raízes lombossacrais pelos elementos degenerados. A descompressão cirúrgica é um procedimento bem estabelecido para pacientes com sintomas severos ou refratários ao tratamento clínico. Contudo, as opções cirúrgicas são amplas. Novas técnicas de fusão e artrodese são úteis para melhorar os resultados funcionais. Neste artigo, varias alternativas cirúrgicas são apresentadas, incluindo as novas tecnologias na área. Evidências científicas mais contundentes com seguimento longo são necessárias para a incorporação destas práticas na atividade médica de rotina.

PALAVRAS-CHAVE: estenose lombar adquirida, tratamento cirúrgico, novas técnicas, fusão.

Lumbar stenosis (LS) is narrowing of any part of the lumbar spinal canal. Absolute stenosis has been defined as an antero-posterior lumbar spine diameter of less than $10 \mathrm{~mm}^{1}$. Although numerical criteria for the diagnosis of LS have been established, the diagnosis can be made without measurements when the narrowing results in clinical symptoms. It is important to note that it is not unusual to encounter patients with radiographic abnormalities who do not have symptoms ${ }^{2}$.

LS can be congenital or acquired. Degenerative disease is the most common cause of acquired stenosis, mainly affecting adults and the elderly. With an increase in life expectancy, there is a concomitant increase in age-relat- ed disease. Although the exact incidence is unknown, it is estimated that LS affects 1 in 1000 patients older than 65 years, being the most common cause of spinal surgery in this group of patients ${ }^{3}$.

Spinal stenosis is secondary to hypertrophy of one or more of the following elements: facet joint, ligamenta flava, posterior longitudinal ligament, intervertebral disc, epidural fat, and osteophytic disease of the vertebral body ${ }^{4,5}$. The degenerative process begins with disc height loss and dehydration, with substitution of collagen type II fibers and proteoglycans for fibrous tissue, with segmental mobility ${ }^{6}$. This results in disc bulging, facet degeneration and hypertrophy, and osteophyte formation that en-

'Department of Neurology, University of Campinas (UNICAMP), Campinas SP, Brazil; '2Department of Neurological Surgery, University of Virginia (UVA), Charlottesville, VA, USA; ${ }^{3}$ Professor of Neurological Surgery, University of Virginia (UVA), Charlottesville, VA, USA. 
croach the spinal canal and/or the lateral recess ${ }^{4,5}$. Facet degeneration may result in degenerative spondylolisthesis with more severe segmental instability ${ }^{7}$. The narrowing can be predominantly central, subarticular (under the facet articulation), or lateral (at the neural foramen). When severe, there can be associated sagittal or coronal deformity.

\section{HISTORY}

LS can cause pain or discomfort in the lower back, buttocks, or legs. These symptoms are predominantly due to lateral recess stenosis. Less commonly, neurogenic claudication (NC) secondary to central canal stenosis can also result in these findings ${ }^{8}$. NC is characterized by leg or thigh pain that is exacerbated with prolonged walking and lumbar extension, which improves with lumbar flexion. In the setting of central canal stenosis, ischemia of the nerve roots may develop from further compression by an engorged venous plexus ${ }^{9}$. Although typical, NC is not pathognomonic of LS. In one report of 62 patients, $92 \%$ presented with lower limb complaints, whereas claudication was detected in $75 \%{ }^{10}$. Rarely one can find sphincter dysfunction due to cauda equina compression, necessitating urgent surgery ${ }^{6}$. The severity of symptoms should be measured using scales, such as the visual analog scale for pain, or the Oswestry low back pain scale ${ }^{11}$.

\section{PHYSICAL EXAM}

Objective neurological findings are not commonly detected on physical examination. The Lasègue test is generally negative, differing LS from acute disc herniation ${ }^{10}$. Lumbar extension can cause discomfort that is relieved with spinal flexion. Muscular weakness is not common, and if present may be due to pain. There may be associated sensory loss in a dermatomal distribution ${ }^{6}$.

\section{DIFFERENTIAL DIAGNOSIS}

A good history and physical examination can help narrow down the differential diagnosis. Hip osteoarthritis may be present when pain is exacerbated by external hip rotation (Patrick's sign or Fabere test - flexion, abduction, external rotation $)^{12}$. Trochanteric bursitis is associated with tenderness over the greater trochanter. Peripheral neuropathy can be associated with sensory deficits in the stocking and glove distribution. Vascular claudication is associated with a decrease in amplitude of the peripheral pulse with trophic changes in the skin. The pain is not altered with spinal flexion or extension, and decreases with rest. Impotence is also associated with vascular claudication. Conus medullaris and/or cauda equina compression by disc herniation, neoplasms, fractures, facet joint syndromes, infectious diseases, and demyelinating diseases are included in the differential diagnosis. Imaging is required to help make the correct diagnosis ${ }^{13,14}$.

\section{RADIOLOGICAL FINDINGS}

The diagnosis of LS is essentially clinical, confirmed by computer tomography (CT) or magnetic resonance (MRI), showing narrowing of the canal and foramina and excluding other elements of the differential diagnosis. While MRI is particularly useful for visualization of the soft tissues resulting in stenosis, CT allows for clear definition of bone anatomy. In our daily practice, we obtain both imaging studies since they are useful for surgical planning. CT myelography may be useful in patients with previous lumbar surgery or in patients in whom MRI is contraindicated. Radiological findings consistent with LS are found in $20 \%$ of asymptomatic patients older than 60 years $^{7}$. The extent of pathology seen on imaging does not necessarily correlate with clinical symptoms ${ }^{2}$.

Standing plain film radiographs (antero-posterior and lateral neutral, flexion, and extension) are essential for surgical planning. These films are required to demonstrate instability. Long cassette standing plain films are also important when one suspects that patients may have associated sagittal or coronal imbalance ${ }^{15}$.

\section{NEUROPHYSIOLOGICAL TESTING}

Electromyography and nerve conduction studies, although not essential, can assist with ruling out lumbosacral plexopathies and peripheral neuropathies from the differential diagnosis. There is a broad spectrum of possible electrophysiological findings in patients with LS. In early stages of the disease normal results may be possible. More advanced disease may demonstrate significantly decreased nerve conduction, with axonal loss and evidence of demyelination in a multi-radicular pattern ${ }^{16-19}$.

\section{TREATMENT}

Before any treatment proposal, it is important to know the natural history of the disease. Most patients have a slowly progressive clinical course, without acute deterioration ${ }^{20,21}$. Johnsson et al. followed 32 patients with moderate LS for 4 years without surgical intervention ${ }^{22}$. They observed that only $16 \%$ had worsening pain; however $30 \%$ had decreased ability to walk.

\section{Non-surgical management}

Spine rehabilitation in the form of physical therapy has been demonstrated to decrease patient symptoms ${ }^{23}$. Exercises that improve abdominal strength may be useful to avoid excessive loading of the lumbar spine, and reduce extension.

There are a variety of ways to obtain non-surgical symptomatic relief. Passive modalities such as heating or cooling pads, lumbar corsets, transcutaneous electrical stimulation (TENS), and ultrasound may provide transient pain relief ${ }^{7}$. Non-steroidal anti-inflammatory med- 
ications or acetaminophen may be used as initial therapy, but when not effective, muscle relaxants and opioids can be used. Anticonvulsants and tricyclic antidepressants are often prescribed as well, but may have adverse effects limiting their use in elderly people. There is no class I evidence to prove the effectiveness of these medications in the treatment of $\mathrm{LS}^{7}$.

Patients not deemed suitable for surgical treatment with persistent radicular pain can benefit from epidural corticosteroid injections (either interlaminar or trans-foraminal). Their effect is attributed to decreasing the inflammation between the nerve root and the elements compressing it. Some patients have a temporary control (weeks to months) of symptoms after having these injections $^{24}$. Despite some controversy associated with the real efficacy of these injections, they are being used at increased frequency around the world and being promoted as a form of safe and minimally invasive treatment ${ }^{25}$.

\section{Surgical treatment}

Patients with persistent symptoms despite non-surgical treatment should be referred to spine surgeons. The goal of surgery is to decompress the spinal canal and neural foramina through laminectomies and partial facetectomies. Many surgical techniques are described in the literature, without a global consensus. There is class I evidence that in patients with persistent symptoms for more than 12 weeks, decompressive surgery (without fusion) improves function and pain control when compared to patients in the non-surgical treatment group. The effects of the surgical procedure were followed for at least 2 years ${ }^{26,27}$.

Since many surgical options to treat LS can be found at the literature, one may find it difficult to choose the optimal procedure. The traditional procedure is a decompressive laminectomy, consisting of removal of the spinous processes, lamina, ligamenta flava, and medial portions of the facet joints ${ }^{26,27}$. Fenestration is a modified partial laminectomy and facetectomy with preservation of the midline structures and the dorsal tension band. Some surgeons advocate its use in patients to prevent iatrogenic instability ${ }^{28}$. It can also be done with minimally invasive techniques.

Regarding fusion and instrumentation procedures, there are no class I studies to prove that fusion and instrumentation improve functional outcomes in patients without criteria of instability. However, there are many papers with class II and III evidence levels advocating concomitant spinal fusion and arthrodesis to improve outcomes and avoid late instabilities, even in patients without spondylolisthesis or spinal deformities ${ }^{29-34}$. It is known that when more than $30 \%$ of the articular facets are removed bilaterally, we have a greater probability of developing late instability, justifying fusion in patients subjected to large decompressive surgeries ${ }^{35}$.
Many instrumentation techniques to achieve fusion can be found in the literature. Pedicle screws with rods and postero-lateral autologous bone fusion have become the standard way to instrument and fuse the lumbar spine. Often, this technique can be supplemented with anterior column support to distract the disc space, and help improve fusion rates. These supplemental techniques are briefly mentioned below and are often utilized in cases with associated segmental instability, revision procedures, sagittal/coronal plane deformities, or severe degenerative disease ${ }^{36,37}$.

1) Posterior lumbar interbody fusion (PLIF): Performed through a posterior approach after pedicle screw insertion. This technique is the earliest form of interbody fusions. When compared to other techniques, it requires greater manipulation of the thecal sac during the placement of the interbody spacer, and may be at higher risk of causing nerve root injury ${ }^{38}$.

2) Transforaminal lumbar interbody fusion (TLIF): Generally performed on the more symptomatic side after pedicle screw insertion. This procedure requires a complete facetectomy and causes less medial displacement of the nerve root during its insertion into the disc space. It has comparable results to other interbody fusions but less morbidity than PLIF. When bilateral facetectomies are performed, the TLIF procedure can improve lumbar lordosis, foraminal height, and sagittal balance ${ }^{36,39}$.

3) Anterior lumbar interbody fusion (ALIF): A complete anterior discectomy is performed using a retroperitoneal or transperitoneal approach. The bone graft or interbody spacer with graft is implanted into the empty disc space. A greater area of arthrodesis is achieved with the ALIF procedure. An additional advantage is its ability to restore lumbar lordosis and foraminal height and improve sagittal balance. The ALIF procedure may or may not require additional posterior instrumentation depending on the individual circumstances of the patient ${ }^{36,40}$.

4) Extreme lateral lumbar interbody fusion (XLIF): A lateral retroperitoneal trans-psoas approach allows discectomy, distraction and interbody fusion in a minimally invasive approach $^{41}$. This technique is usually supplemented by pedicle screws. Advantages of the XLIF are the lack of need for an approach surgeon and the ability to treat multiple levels from a small incision. However, it is not capable of reaching the L5 S1 disc space. Long term follow-up is needed to assess its ultimate outcome.

\section{Bone grafts and adjuncts to fusions}

The ultimate goal of instrumentation is to correct deformity and achieve fusion. Cancelous autologous bone is the most effective graft, since it contains osteogenic cells, and is both osteoinductive and osteoconductive. However, harvesting autograft bone is also associated with sur- 
gical morbidity, especially when obtained from the iliac crest $^{42}$. Because of morbidity associated with bone graft harvesting, many substitutes are being studied. One of their disadvantages is the high cost and limited long term follow-up. Cadaveric allograft bone has osteoconductive and osteoinductive properties, but very limited osteogenic cells. It has an extremely low risk of disease transmission such as hepatitis $C$ and aids ${ }^{43}$. New generations of allograft bone, such as a demineralized bone matrix, have been shown to have osteoinductive properties in animal studies. Although the efficacy in patients to achieve fusion has been established, long term results have not been performed to determine it ultimate utility ${ }^{44}$.

The use of growth factors such as members of the bone morphogenetic protein (BMP) family to enhance spinal arthrodesis has gradually increased in the last several years. These growth factors are proteins that induce the differentiation of undifferentiated stem cells to osteoblasts. They have a very short half-life, and must be administered in high doses with a carrier (collagen sponge). Recombinant human BMP-2 (rhBMP-2) has been primarily investigated in lumbar spine fusions, where it has significantly enhanced the fusion rate and decreased the length of surgery, blood loss, and hospital stay. Its practical application is limited by the significant cost of application, which can be up to U\$7000 per fusion level ${ }^{45,46}$. Despite the early enthusiasm researchers expressed for using rhBMP-2 to enhance spinal fusion, there are significant risks associated with using BMP's supraphysiological doses including inflammatory reaction, effusion, seroma, ectopic bone formation and other untoward side effects not appreciated earlier in their use ${ }^{47}$. BMP-2 has been approved by the FDA for its use in conjunction with threaded cages and bone dowels for singlelevel ALIFs, and has been successfully used in postero-lateral fusion associated with local bone or bone expander ${ }^{48}$.

\section{New surgical alternatives to fusion}

1) Lumbar disk replacement: The rationale for its use is to decrease adjacent level degeneration after fusion procedures. There are two systems approved in the US for clinical use ${ }^{49}$. For stable single level symptomatic disc degeneration unresponsive to conservative treatment (with good bone quality), total disk replacement may be an alternative to fusion ${ }^{50}$. There is controversy regarding its routine use in the US.

2) Interspinous spacer: The objective of this device is to provide a flexion-distractive force in the posterior elements of the spine, relieving symptoms secondary to narrowing of the spinal canal and neural foramina in patients without spondylolisthesis or grade I spondylolisthesis ${ }^{51}$. There are data suggesting that surgical results are similar to lumbar decompression surgery at 4 year follow-up with less hospital costs ${ }^{52}$. In carefully selected patients this may be an alternative to non-instrumented lumbar decompression.

3) Dynamic stabilization: This system consists of a pedicle screw construct with a polyethylene cord and polyurethane spacer connecting the screws instead of metal rods, hence permitting some motion. No bone grafting is necessary in light of the concept of motion preservation to theoretically avoid adjacent level degenerative disease. Welch et al. in 2007 demonstrate good results as an alternative to fusion ${ }^{53}$.

4) Nucleus pulposis replacement: This is biomechanically similar to a native nucleus pulposis. The replacement nucleus pulposis is a hydrogel pellet encased in a polyethylene jacket that is capable of absorbing impact and maintaining disc height. It is under preliminary analysis. General indications have not been clearly defined ${ }^{54}$.

In conclusion, LS has a broad spectrum of potential treatment options since there is a broad spectrum of disease severity. Accurate diagnosis is extremely important for good clinical results. The appropriate treatment strategy is determined by carefully evaluating the specific circumstances of each patient. Steroids injections and rehabilitation programs are established non-surgical modalities to help improve the symptoms of patients with LS. After attempts of conservative management, surgery is the best option in selected patients with positive radiographic findings and appropriate clinical correlation. Depending upon various factors, fusion may be necessary. New techniques and technologies in spinal surgery are constantly being developed to potentially improve surgical results. More long term studies of new technologies will be needed to determine the optimal treatment.

\section{REFERENCES}

1. Verbiest $H$. Neurogenic intermittent claudication in cases with absolute and relative stenosis of the lumbar vertebral canal (ASLC and RSLC), in cases with narrow lumbar intervertebral foramina, and in cases with both entities. Clin Neurosurg 1973;20:204-214.

2. Boden SD, McCowin PR, Davis DO, Dina TS, Mark AS, Wiesel S. Abnormal magnetic-resonance scans of the lumbar spine in asymptomatic subjects: a prospective investigation. J Bone Joint Surg Am 1990;72:403-408.

3. Ciol MA, Deyo RA, Howell E, Kreif S. An assessment of surgery for spinal stenosis: time trends, geographic variations, complications, and reoperations. J Am Geriatr Soc 1996;44:285-290.

4. Kirkaldy-Willis WH, Wedge JH, Yong-Hing K, et al. Pathology and pathogenesis of lumbar spondylosis and stenosis. Spine 1978;3:319-328.

5. Yong-Hing K, Kirkaldy-Willis WH. The pathophysiology of degenerative disease of the lumbar spine. Orthop Clin North Am 1983;14:491-504. 
6. Sheehan JM, Shaffrey CI, Jane JA Sr. Degenerative lumbar stenosis: the neurosurgical perspective. Clin Orthop Relat Res 2001;384:61-74.

7. Katz JN, Harris MB. Lumbar spinal stenosis. N Engl J Med 2008;358:818-825.

8. Jane Jr JA, di Pierro CG, Helm GA, Shaffrey CI, Jane Sr JA. Acquired lumbar stenosis: topic review and a case series. Neurosurg Focus 1997;3:E11.

9. Jespersen S, Hansen E, Høy K, et al. Two-level spinal stenosis in minipigs: hemodynamic effects of exercise. Spine 1995;20:2765-2773.

10. Deburge A, Morvan G. L'imagerie dans les sténoses du canal lombaire. Rev Chir Orthop 1990;76:45-49.

11. Fairbank JCT, Pinsent PB. The Oswestry Disability Index. Spine 2000;25:2940-2953.

12. Kenna C, Murtagh J. Patrick or fabere test to test hip and sacroiliac joint disorders. Aust Fam Physician 1989;18:375.

13. Joaquim AF. Abordagem inicial do paciente com mielopatia aguda não compressiva. Rev Bras Medicina 2007;64:164-168.

14. Joaquim AF, Maturana FAP, Anderle DV, Zambelli HJL, Maldaun MVC. Metástases na coluna vertebral. Rev Neurocienc 2007;15:240-245.

15. Glassman SD, Bridwell K, Dimar JR, et al. The impact of positive sagittal balance in adult spinal deformity. Spine 2005; 30:2024-2029.

16. Videman T, Malmivaara A, Mooney V. The value of axial view in assessig diskograms: an experimental study with cadavers. Spine 1987;12:299-304.

17. Nardin RA, Patel MR, Gudas TF, Rutkove SB, Raynor EM. EMG and MRI in the evaluation of radiculopathy. Muscle Nerve 1999;22:151-155.

18. Dumitru D, Zwarts MJ. Radiculopathies. In Dumitru D, Amato AA, Zwarts MJ (Eds). Electrodiagnostic medicine. $2^{\text {nd }}$ Ed. Philadelphia: Hanley and Belfus 2002:757-758.

19. Haig AJ, Tong HC, Yamakawa KS,et al. The sensitivity and specity of electrodiagnostic testing for the clinical syndrome of lumbar spinal stenosis. Spine 2005;30:2667-2676

20. Atlas SJ, Keller RB, Robson D, Deyo RA, Singer DE. Surgical and nonsurgical management of lumbar spinal stenosis: fouryear outcomes from the Maine Lumbar Spine Study. Spine 2000;25:556-562.

21. Simotas AC, Dorey FJ, Hansraj KK, Cammisa F Jr. Nonoperative treatment for lumbar spinal stenosis: clinical and outcome results and a 3-year survivorship analysis. Spine 2000;25:197-204.

22. Johnsson KE, Rosen I, Uden A. The natural course of lumbar spinal stenosis. Clin Orthop 1992;279:82-86.

23. Whitman JM, Flynn TW, Childs JD, et al. A comparison between two physical therapy treatment programs for patients with lumbar spinal stenosis: a randomized clinical trial. Spine 2006;31:2541-2549.

24. Armon C, Argoff CE, Samuels J, Backonja MM. Assessment: use of epidural steroid injections to treat radicular lumbosacral pain: report of the Therapeutics and Technology Assessment
Subcommittee of the American Academy of Neurology. Neurology 2007;68:723-729.

25. Friedly J, Chan L, Deyo R. Increases in lumbosacral injections in the medicare population 1994 to 2001. Spine 2007;32: 1754-1760.

26. Weinstein JN, Tosteson TD, Lurie JD, et al. SPORT Investigators. Surgical versus nonsurgical therapy for lumbar spinal stenosis. N Engl J Med 2008;358:794-810.

27. Malmivaara A, Slatis P. Surgical or nonoperative treatment for lumbar spinal stenosis? A randomized controlled trial. Spine 2007;32:1-8.

28. Oertel MF, Ryang YM, Korinth MC, Gilsbach JM, Rohde V. Long-term results of microsurgical treatment of lumbar spinal stenosis by unilateral laminotomy for bilateral decompression. Neurosurgery 2006;59:1264-1269.

29. Resnick DK, Choudhri TF, Dailey AT, et al. Guidelines for the performance of fusion procedures for degenerative disease of the lumbar spine. Part 10: fusion following decompression in patients with stenosis without spondylolisthesis. J Neurosurg Spine 2005;2:686-691.

30. Yone K, Sakou T, Kawauchi Y, Yamaguchi M, Yanase M. Indication of fusion for lumbar spinal stenosis in elderly patients and its significance. Spine 2006;21:242-248.

31. Fox MW, Onofrio BM, Hanssen AD. Clinical outcomes and radiological instability following decompressive lumbar laminectomy for degenerative spinal stenosis: a comparison of patients undergoing concomitant arthrodesis versus decompression alone. J Neurosurg 1996,85:793-802.

32. Herkowitz HN, Kurz LT. Degenerative lumbar spondylolisthesis with spinal stenosis: a prospective study comparing decompression with decompression and intertransverse process arthrodesis. J Bone Joint Surg Am 1991;73:802-808.

33. Katz JN, Dalgas M, Stucki G, et al. Degenerative lumbar spinal stenosis: diagnostic value of the history and physical examination. Arthritis Rheum 1995;38:1236-1241.

34. Katz JN, Lipson SJ, Lew RA, et al. Lumbar laminectomy alone or with instrumented or noninstrumented arthrodesis in degenerative lumbar spinal stenosis: patient selection, costs, and surgical outcomes. Spine 1997;22:1123-1131.

35. Selby DK, Gill K, Blumenthal SL, et al. Fusion of the lumbar spine. In Youmans JR (Ed). Neurological surgery. $3^{\text {rd }}$ Ed. Philadelphia: WB Saunders, 1990:2785-2804.

36. Hackenberg L, Halm H, Bullmann V, et al. Transforaminal lumbar interbody fusion: a safe technique with satisfactory three to five year results. Eur Spine J 2005;14:551-558.

37. Pavlov PW, Meijers H, van Limbeek J, et al. Good outcome and restoration of lordosis after anterior lumbar interbody fusion with additional posterior fixation. Spine 2004;29:1893-1899.

38. Periasamy K, Shah K, Wheelwright EF. Posterior lumbar interbody fusion using cages, combined with instrumented posterolateral fusion: a study of 75 cases. Acta Orthop Belg 2008;74: 240-248.

39. Salehi SA, Tawk R, Ganju A, et al. Transforaminal lumbar in- 
terbody fusion: surgical technique and results in 24 patients. Neurosurgery 2004;54:368-374.

40. Hsieh PC, Koski TR, O'Shaughnessy BA, et al. Anterior lumbar interbody fusion in comparison with transforaminal lumbar interbody fusion: implications for the restoration of foraminal height, local disc angle, lumbar lordosis, and sagittal balance. J Neurosurg Spine 2007;7: 379-386.

41. Ozgur BM, Aryan HE, Pimenta L, Taylor WR. Extreme Lateral Interbody Fusion (XLIF): a novel surgical technique for anterior lumbar interbody fusion. Spine J 2006;6: 435-443.

42. Ahlmann E, Patzakis M, Roidis N, Shepherd L, Holtom P. Comparison of anterior and posterior iliac crest bone grafts in terms of harvest-site morbidity and functional outcomes. J Bone Joint Surg Am 2002;84:716-720.

43. Zipfel GJ, Guiot BH, Fessler RG. Bone grafting. Neurosurg Focus 2003;14:E8.

44. Schizas C, Triantafyllopoulos D, Kosmopoulos V, Tzinieris N, Stafylas K. Posterolateral lumbar spine fusion using a novel demineralized bone matrix: a controlled case pilot study. Arch Orthop Trauma Surg 2008;128:621-625.

45. Boden SD, McCowin PR, Davis DO, et al. Abnormal magneticresonance scans of the lumbar spine in asymptomatic subjects: a prospective investigation. J Bone Joint Surg Am 1990;72:403-408.

46. Hsu WK, Wang JC. The use of bone morphogenetic protein in spine fusion. Spine J 2008;8: 419-425.

47. Shields LB, Raque GH, Glassman SD, et al. Adverse effects as- sociated with high-dose recombinant human bone morphogenetic protein-2 use in anterior cervical spine fusion. Spine 2006;31:542-547.

48. Glassman SD, Carreon L, Djurasovic M, et al. Posterolateral lumbar spine fusion with INFUSE bone graft. Spine J 2007;7: 44-49.

49. Shim CS, Lee SH, Shin HD, et al. Charite versus ProDisc: a comparative study of a minimun 3-year follow-up. Spine 2007; 32:1012-1018.

50. Guyer RD, McAfee PC, Hochschuler SH, et al. Prospective randomized study of the Charite artificial disc: data from two investigational centers. Spine J 2004;4:252-259.

51. Andeson PA, Tribus CB, Kitchel SH. Treatment of neurogenic claudication by interspinous decompression: application of the X STOP device in patients with lumbar degenerative spondylolisthesis. J Neurosurg Spine 2006;4:463-471.

52. Kondrashov DG, Hannibal M, Hsu KY, Zucherman JF. Interspinous process decompression with the X-STOP device for lumbar spinal stenosis: a 4-year follow-up study. J Spinal Disord Tech 2006;19:323-327.

53. Welch WC, Cheng BC, Awad TE, et al. Clinical outcomes of the Dynesys dynamic neutralization system: 1-year preliminary results. Neurosurg Focus 2007;22:E8.

54. Siepe CJ, Mayer HM, Wiechert K, Korge A. Clinical results of total lumbar disc replacement with ProDiscII: three-year results for different indications. Spine 2006;31:1923-1932. 